\title{
Medição de perda e produtividade de argamassa industrializada no serviço de revestimento de fa- chada
}

Industrialized mortar loss and productivity in the façade cladding

Caetano, A. S.

Escola Politécnica de Pernambuco Universidade de Pernambuco 50.720-001 - Recife, Brasil alissoncaetanodasilva@hotmail.com

\author{
Lordsleem Jr, A. C. \\ Escola Politécnica de Pernambuco \\ Universidade de Pernambuco \\ 50.720-001 - Recife, Brasil \\ acasado@poli.br
}

Resumo A medição do desempenho da execução do revestimento de argamassa de fachada deve merecer especial atenção na construção de edifícios, pois representa parcela expressiva do custo total e condiciona o prazo da obra. Dentro desse contexto, este artigo tem como principal objetivo apresentar os resultados do monitoraramento do desperdício de argamassa industrializada e a produtividade da mão de obra na execução do revestimento de argamassa de fachadas de edifi-cios.

Palavras-Chave: Desperdício, produtividade, argamassa, fachada, construção civil

\begin{abstract}
Performance measurement of the façade mortar coating should deserve special attention in building construction, as it represents a significant portion of the building total cost and produc-tivity. Within this context, this research has as main objective to monitor the mortar loss and labor productivity in the execution of building facades.
\end{abstract}

Keywords: Loss, productivity, mortar, façade, civil construction 


\section{Introdução}

Este artigo resultante de trabalho desenvolvido em iniciação científica fez parte de um projeto de pesquisa que está associado a uma Dissertação de mestrado do Programa de Pós-Graduação em Engenharia Civil da PO$\mathrm{LI} / \mathrm{UPE}$.

A medição de desempenho na indústria da construção é uma prática relativamente recente, tendo recebido forte impulso pela implantação e certificação de sistemas de gestão da qualidade pelas empresas construtoras (DUARTE, 2011). As normas NBR ISO 9001 e do Sistema de Avaliação da Conformidade de Empresas de Serviços e Obras da Construção Civil (SiAC) do Programa Brasileiro de Qualidade e Produtividade no Habitat (PBQP-H) contem exigências específicas relativas à medição de desempenho. Os sistemas de medição de desempenho fornecem informações essenciais para o planejamento e controle dos processos gerenciais e o monitoramento dos objetivos e metas estratégicas da empresa.

\section{Material de estudo}

Como componente da envoltória do edifício, o re-vestimento de emboço de fachada tem uma estreita rela-ção com os mais diversos subsistemas da edificação, como, por exemplo, estrutura de concreto armado e alve-naria de vedação. Além disso, o emboço possui funções que o tornam de vital importância para o edifício, não só esteticamente, mais também com relação ao desempenho deste, mais que regularizar a fachada, o emboço veda e protege o edifício, inibindo a penetração de agentes a-gressivos.

A importância das funções exercidas pelo revestimento de emboço de fachada, bem como a influência que representa nos custos da obra, remetem a necessidade de estudar a mão de obra envolvida na execução deste serviço.

Em se tratando do desperdício da argamassa parcialmente ou totalmente produzida fora do canteiro para emboço ou massa única, Agopyan et al. (1998) apresen-tam os resultados de pesquisa em 04 obras, cujo valor médio foi de $99 \%$; enquanto, o mínimo de desperdício foi de 5\% e o máximo atingiu $209 \%$. Percebeu-se uma dis-persão muito elevada dos resultados, remetendo a neces-sidade de estudos mais detalhados para a obtenção de dados condizentes com a realidade de cada situação.

Diante disto, verifica-se a importância do estudo do desperdício de argamassa e da produtividade da mão-deobra envolvida na execução do revestimento de argamassa de fachada, já que este serviço envolve a execução de subetapas, constitui funções importantes e custos representativos para a edificação como um todo.

\section{Metodologia}

Etapa 01 - levantamento bibliográfico: identifican-do a literatura sobre medição de desempenho; indicado-res de consumo, perdas e produtividade; benchmarking, através de consulta: artigos de revistas nacionais e in-ternacionais, normas, sites na internet de institutos de pesquisa e associações de construção. Essa fase foi de grande importância pois aprendi muito sobre o serviço de emboço de fachada , onde existe uma grande relação e importância para a vida útil da construção o revesti-mento externo desempenha. Outro grande aprendizado que pude ganhar foi conhecer melhor um indicador de produtividade chamado RUP (razão unitária de produ-ção), onde ele é a razão então a quantidade de horas trabalhadas pela quantidade de serviço feito nesse inter-valo de tempo. Quanto maior for o valor pior é a produ-tividade.

Etapa 02: análise de indicadores de desempenho, definição de metodologia de coleta de dados: conhecimento e definição do sistema de medição de desempenho. A metodologia empregada para medir as perdas de argamassa industrializada e a produtividade foi antes discutida em são Paulo, são usadas planilhas bem simples para que qualquer estagiário ou encarregado treinado possa também preenche-las . Nelas colocamos as quantidades de serviço da semana medida $\mathrm{em} \mathrm{m}^{2}$, as horas trabalhadas de cada pedreiro e servente, o $\mathrm{s}$ estoque de argamassa presente na obra e o que chegou durante a semana. Assim com esses dados pode-se calcular a as RUPs e perdas de argamassa.

Etapa 03 - monitoramento dos indicadores: acompanhamento sistemático dos resultados gerados em 03 obras para a análise, a comparação e a identificação das melhores práticas. Essa é a presente etapa se encontra o projeto, sendo reali-zada a coleta em 1 obra.

Etapa 04: identificação e caracterização das melhores práticas: descrição detalhada das melhores práticas (produtos, serviços e métodos de trabalho), com o propósito de melhoria organizacional que conduz à superioridade competitiva.

Etapa 05: diretrizes para a adoção das melhores práticas: estabelecimento das principais ações necessárias que promovam maiores possibilidades de sucesso na implantação das melhores práticas no serviço de revesti-mento de argamassa de fachada. 


\section{Resultados obtidos}

Os resultados obtidos estão expressos nas Figuras 1, 2 e 3. Esses valores refletem a coleta de dados de apenas uma obra. A unidade da medida da produtividade foi a RUP (Razão Unitária de Produção).

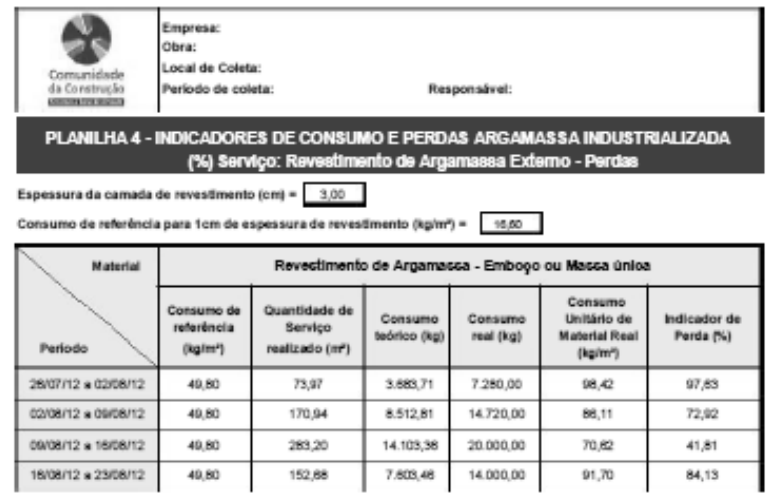

Figura 1. Resultados de perdas

\begin{tabular}{|c|c|c|c|c|}
\hline \multirow[b]{2}{*}{$\begin{array}{c}\text { Semanas coletadas } \\
\text { (Data) }\end{array}$} & \multicolumn{4}{|c|}{ Emboço ou m3ssa unica ( $m^{7}$ ) } \\
\hline & $Q S_{\mathrm{cm}}(\mathrm{m})$ & $\mathrm{Hh}_{\mathrm{em}}$ dilreta & RUP8 $_{\text {bom }}$ direta & RUPC $_{\text {sem }}$ direta \\
\hline $26 / 07 / 12$ a $02 / 08 / 12$ & 73,12 & 63,00 & 0,86 & 0,86 \\
\hline $02 / 08 / 12$ a 09/08/12 & 170,94 & 133,00 & 0,78 & 0,80 \\
\hline $09 / 08 / 12$ a $16 / 08 / 12$ & 283,00 & 176,00 & 0,62 & 0,71 \\
\hline $16 / 08 / 12$ a $23 / 0812$ & 152,68 & 88,00 & 0,58 & 0,68 \\
\hline Total & 679,74 & 460,00 & 0,68 & 0,68 \\
\hline
\end{tabular}

Figura 2. Resultados de produtividade - Pedreiro

\begin{tabular}{|c|c|c|c|c|}
\hline & \multicolumn{4}{|c|}{ Emboço ou massa ùnica ( $m^{2}$ ) } \\
\hline (Data) & $Q S_{o m}(m)$ & $\mathrm{Hh}_{\mathrm{em}}$ direta & RUP $_{\mathrm{cem}}$ direta & RUPCesm dirata \\
\hline $26 / 07 / 12$ a $02 / 08 / 12$ & 73,12 & 63,00 & 0,86 & 0,86 \\
\hline $02 / 08 / 12$ a $09 / 08 / 12$ & 170,94 & 106,00 & 0,62 & 0,69 \\
\hline $09 / 08 / 12$ a $16 / 08 / 12$ & 283,00 & 132,00 & 0,47 & 0,57 \\
\hline $16 / 08 / 12$ a $23 / 0812$ & 152,68 & 44,00 & 0,29 & 0,51 \\
\hline Total & 679,74 & 345,00 & 0,51 & 0,51 \\
\hline
\end{tabular}

Figura 3. Resultados de produtividade - Servente

Nota-se com os resultados apresentados que se chega até perda de quase $100 \%$ ou seja o dobro orçado pela construtora. Por isso é de grande importância ter um monitoramento do serviço de revestimento em argamas-sa.

A partir dos resultados obtidos se teve uma ideia de como é grande a perda de argamassa industrializada e o quanto a mão de obra ainda está longe do esperado para uma eficiente produção - produtividade variável.

\section{Conclusão}

O estudo foi de grande importância, mostrando-se bastante prático, servindo como subsídio para a tomada de decisão por parte da empresa construtora.

Como verificado nos resultados, ainda está longe o que é previamente orçado para a obra com a realidade do orçamento inicial.

\section{Referências}

[1] AGOPYAN, V.; SOUZA, U.E.L.; PALIARI, J.C.; ANDRADE, A.C. Alternativas para redução do desperdício de materiais nos canteiros de obra, 1998. Disponível em: http://habitare.infohab.org.br/pdf/publicacoes/ar quivos/104.p df. Acesso em: 01 fev. 2009.

[2] BAÍA, L.L.M.; SABBATINI, F.H. Projeto e execução de revestimento de argamassa. São Paulo: O Nome da Rosa, 2000.

[3] BARKOKEBAS JUNIOR, B.; LORDSLEEM JR., A.C.; SILVA, B. M. V.; DUARTE, C. M. M. Sistemas de gestão em segurança e saúde do trabalho e de gestão da qualidade na construção civil. Recife: EDUPE, 2009. v. 1. 126 p.

[4] CAVALCANTI, R.F.V. Uma investigação sobre medidas de desempenho utilizadas pelas empresas de construção civil, subsetor edificações, na região metropolitana de Recife. 110p. Dissertação (Mestrado) - Programa multi-institucional UnB/UFPB/UFPE/URFN. Recife, 2004.

[5] COSTA, D.B.. Diretrizes para concepção, im-plementação e uso de sistemas de indicadores de desempenho para empresas de construção civil. 176f. Dissertação (Mestrado) - Escola de Engenharia, Universidade Federal do Rio Grande do Sul. Porto Alegre, 2003.

[6] COSTA, D.B. et al. Sistema de indicadores para benchmarking na construção civil: manual de utilização. Porto Alegre: UFRGS/PPGEC/NORIE, 2005.

[7] DUARTE, C.M. Desenvolvimento de sistema de indicadores para benchmarking em empresas de 
construção civil. 250 p. Dissertação (Mestrado) Universidade de Pernambuco. Recife, 2011. 